This item was submitted to Loughborough's Research Repository by the author.

Items in Figshare are protected by copyright, with all rights reserved, unless otherwise indicated.

\title{
Soft systems methodology for performance measurement in the Uganda water sector
}

PLEASE CITE THE PUBLISHED VERSION

http://www.iwaponline.com/wp/01003/wp010030273.htm

PUBLISHER

(C) IWA Publishing

VERSION

AM (Accepted Manuscript)

LICENCE

CC BY-NC-ND 4.0

REPOSITORY RECORD

Kayaga, Sam. 2019. "Soft Systems Methodology for Performance Measurement in the Uganda Water Sector". figshare. https://hdl.handle.net/2134/9954. 
This item was submitted to Loughborough's Institutional Repository (https://dspace.lboro.ac.uk/) by the author and is made available under the following Creative Commons Licence conditions.

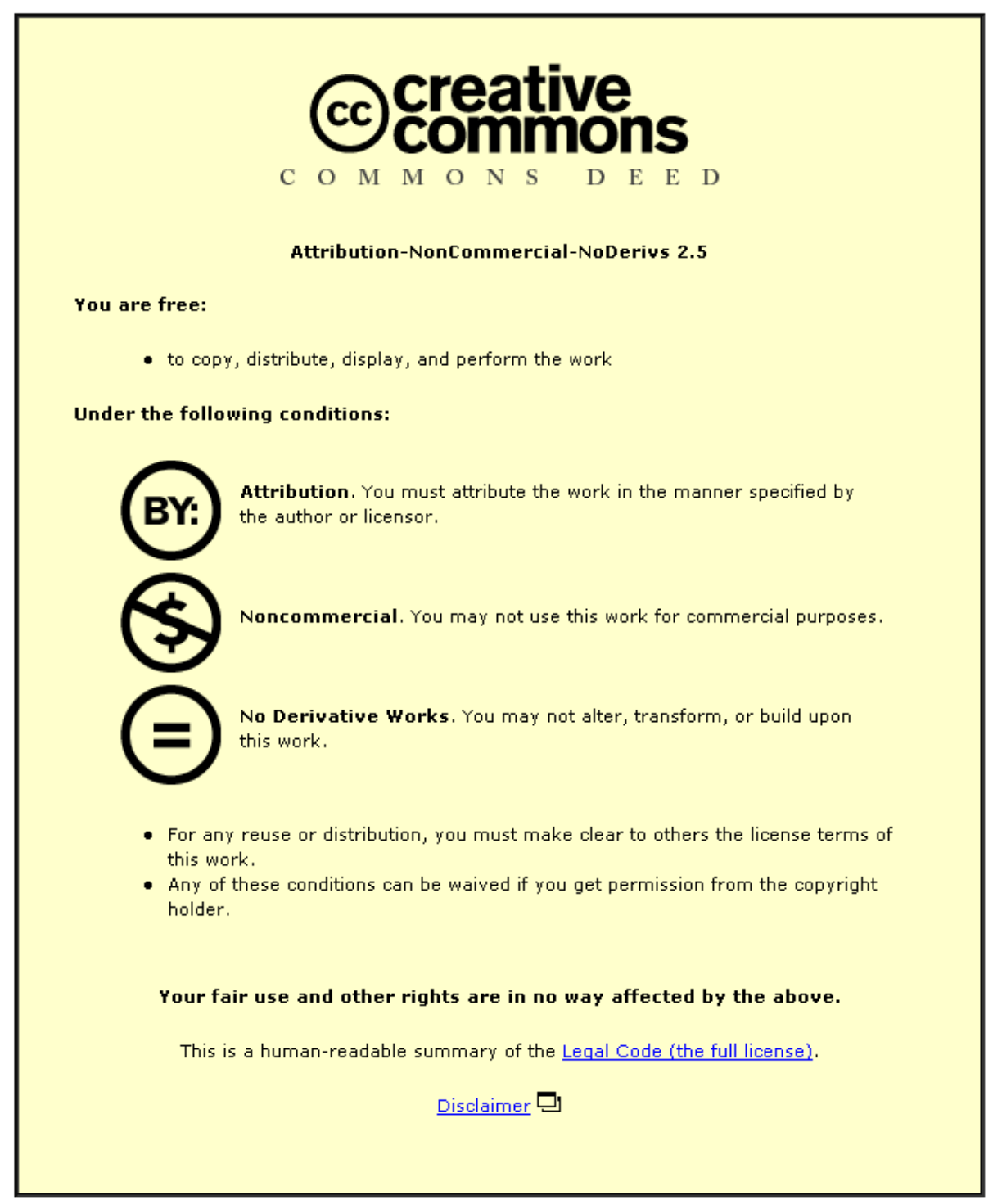

For the full text of this licence, please go to: http://creativecommons.org/licenses/by-nc-nd/2.5/ 
Soft systems methodology for performance measurement in the Uganda water sector

Sam Kayaga

Water, Engineering and Development Centre (WEDC), Department of Civil and Building Engineering, Loughborough University, Leicestershire, LE11 3TU, UK. Fax: +44-1509 211079. E-mail: s.m.kayaga@Lboro.ac.uk

Received 16 June 2006; accepted in revised form 5 September 2006

\begin{abstract}
Water and sanitation services in developing countries are delivered in an extremely complex institutional environment, characterised by "soft" problems, that is problems with significant political and social components whose "what" and "how" cannot be defined early in the intervention process. A problem situation common in developing countries depicting "soft" characteristics is how to improve the effectiveness and efficacy of existing performance measurement systems to track the progress towards achievement of water/sanitation-related Millennium Development Goals (MDGs). Such problem situations are better handled using soft systems methodology (SSM), a methodology recommended by Professor Checkland and his research colleagues at Lancaster University, UK. In 2003, SSM was applied in an intervention that aimed to improve performance measurement systems in the Uganda water/sanitation sector. Through strong participation of the key stakeholders, a team of researchers with their local counterparts in Uganda developed and field tested a performance measurement framework. According to an evaluation by the international donor community, policy makers and managers in the sector, the past three annual water/sanitation sector performance reports compiled using the
\end{abstract}


performance measurement framework have depicted a progressive qualitative improvement.

Keywords: Action learning; Developing countries; Performance measurement; Soft systems methodology; Water and sanitation sector

\section{Introduction}

One of the targets set under the Millennium Development Goals (MDGs) is to reduce by half, the proportion of people without access to safe drinking water and basic sanitation by 2015. At the beginning of the millennium, it was estimated that 1.1 billion and 2.4 billion people, the majority of whom lived in developing countries, lacked access to safe drinking water and basic sanitation, respectively (WHO/UNICEF, 2000[this reference is not given in the reference list. Please provide full details or delete citation]). Access to safe drinking water and improved sanitation does not only enhance environmental integrity; it is also critical to achieving the UN's overarching goal of poverty eradication and the Millennium targets for health, education and promotion of gender equality and women empowerment. WHO estimated that about US\$13.7 billion is required to achieve the MDG target for access to safe drinking water and improved sanitation using minimum cost solutions (Evans et al., 2004). Besides the enormity of resources required, an issue of concern preoccupying water sector policy makers and managers in many low-income countries is how the available resources can best be utilised to achieve an optimum outcome.

One key obstacle to early achievement of the MDG is the prevalence of inconsistencies, gaps and disconnections in the water and sanitation sector monitoring mechanisms (WELL, 2004). To reduce such inconsistencies, Uganda set out in 2003 
to improve the water and sanitation sector performance measurement framework, a process that is still on-going. Performance measurement of the sector may achieved through assessment of four parameters (Checkland \& Scholes, 1990; Robinson \& Thin, 1993; Thomson et al., 2006;): (1) economy, that is whether inputs of the right quality have been obtained at the right price; (2) efficiency, that is whether the conversion of inputs into outputs has been achieved with as few resources as possible; (3) effectiveness, that is whether the desired objectives set in the original plan have been achieved; and (4) efficacy, that is the apparent worth or value of an intervention, closely associated with the concept of user satisfaction. This paper describes how soft systems methodology (SSM), an action research and learning process approach was used to bring together existing diverse performance measurement regimes in the Uganda water and sanitation sector and harmonise them into an improved performance measurement framework.

\section{What is soft systems methodology (SSM)?}

Engineers and physical science professionals, who are the dominating professionals in the water and sanitation sector, are principally trained in the physical sciences and spend most of their vocational life dealing with hard problems. These are problems which can easily be defined technically and their "what" and "how" can be determined earlier on in the methodology (Checkland, 1993; Couprie et al., 2005). In contrast, soft problems, which have a significant social and political component, are complex and difficult to define. By assuming that the world consists of a set of interacting systems, the systems engineering approach has been highly successful in solving the hard problems (Wilson, 1984). Peter Checkland and his research colleagues at Lancaster University, UK set out in the early 1970s to test out whether the systems engineering approach could also be successfully applied by managers to a 
real world situation perceived to be complex and confused. Although systems engineering could not directly be transferred to the broader issues of management, Checkland and colleagues adapted the systems-based, action research methodology to develop an alternative approach. Soft systems methodology (SSM) is "an organised way of tackling messy situations in the real world" (Checkland, 1985; Checkland \& Scholes, 1990: p 1).

The research work by Checkland and his research colleagues highlighted the distinction between "hard" and "soft" systems thinking. In "hard" systems thinking, parts of the world are assumed to be systems, some of which do not work well and can be engineered to work better (Wilson, 1984). In contrast, "soft" systems thinking perceives the world as complex, problematic and confused and in order to cope with it, focuses on making the process of inquiry itself a system for learning. Water supply and sanitation services in low-income countries are provided in an extremely complex institutional environment and application of SSM to the reform process could provide a powerful tool for understanding and rationalising the institutional environment (Seppälä, 2002). SSM is indeed suitable for application to public sector problems that are complex and messy (Grigg, 1997; Khisty, 1995).

Originally, SSM was presented as an engineering-like sequence of seven activities in a circular learning process. As action research progressed, the seven-stage model was simplified into four key distinct but interactive stages of action, which could be presented as a simplified diagram, shown in Figure 1.

The four main activities of SSM shown in Figure 1 could briefly be described as (Checkland, 1999; Checkland \& Scholes, 1990; Couprie et al., 2005): 
1 finding out about the problem situation in the real world that has generated concern, including the analysis of its cultural and political context and expressing the problem situation in a way that maximises visual communication;

2 formulating some relevant purposeful activity models;

3 comparing the models with the real-world situation and utilising the debate initiated by the comparison to seek (i) changes that are regarded as both desirable and culturally feasible, to improve the situation and (ii) accommodations between conflicting interests so that action is not hampered; and 4 taking action to bring about improvement in the world situation, which would culminate in a cyclic process.

Section 3 below provides a background to the institutional setup of the Uganda water and sanitation sector. Sections 4-7 describe how the SSM stages were adapted in the process of improving the performance measurement framework for the water and sanitation sector in Uganda.

\section{Institutional set-up of the Uganda water and sanitation sector}

Uganda is a sub-Saharan country with a GDP per capita of US\$1,457, with a population of 26.9 million people in $2003,55 \%$ of which were estimated to be living below the national poverty line (UNDP, 2005). Uganda's national economic policies geared towards poverty alleviation have since 1987 been grounded in the Poverty Eradication Action Plan (PEAP), Uganda's version of the World Bank sponsored Poverty Reduction Strategy Paper (PRSP), whose overarching goal is to reduce headline poverty to not more than $10 \%$ by 2017 (Government of Uganda, 2003a; 2004a). Since then, policies, strategies and plans for key sectors have been designed as off-shoots of the PEAP, which has been kept current through regular revisions. The water and sanitation sector is one of the priority areas which benefit from the Poverty 
Action Fund (PAF), a dedicated fund that is mainly replenished by donor funds channelled through the highly indebted poor countries (HIPC) credit. The Uganda government also contributes a large proportion of its capital expenditure to this fund. Water and sanitation sector interventions directly contribute to two of the four pillars of PEAP, namely, actions which directly increase the ability of the poor to raise their incomes, and actions which directly improve the quality of life of the poor.

The Uganda water and sanitation sector is of composed of four key institutions: (1) the Directorate of Water Development is the leading policy-making agency and is in charge of rural water supply, urban water supply for small towns of population of below 10,000 people, water for production and water resources; (2) National Water and Sewerage Corporation, a government-owned parastatal that provides water supply and sewerage services in the country's larger towns; (3) Environmental Health Division of the Ministry of Health that oversees household sanitation; and (4) a section of in the Ministry of Education looking after school sanitation. Different institutions in the sector have in the past made individual strategic plans and budgets, with hardly any inter-organisational coordination. In extreme cases, different sections in the Directorate of Water Development, the water lead agency, carried out numerous donor-funded projects in a disjointed manner, with no central planning. Since 2001, a sector-wide approach to policy making, planning and budgeting has been adopted and a Water and Sanitation Sector Working Group (WSSWG), with representatives from all the sector institutions, water-based NGOs and the international donor community coordinate activities across the whole sector. The sector working group works through various more discipline-specialised structures in form of sub-sector working groups, thematic teams and steering groups. 
The sector working group is responsible for formulating a sector investment plan, overall targets and budgets for the period up to 2015 .

\section{Performance measurement in the water sector: a problem situation}

In recognition of the overarching importance of water and sanitation services in achieving the MDG and the national PEAP, the government of Uganda has substantially increased the resources provided to the water and sanitation sector, in the past few years. For instance, annual investment financial flows to the sector increased from US\$ 32 million in 1997 to US\$ 79 million in 2003 (Government of Uganda, 2004b). Various stakeholders have in the past expressed dissatisfaction with the way these funds were spent. There were two main points of contention. First, performance measurement in the sector focused on review of inputs and outputs, separately, without assessing the link between inputs and outputs and did not verify whether outcome and impact objectives had been realised. Second, although there were a magnitude of efforts to measure sector performance at the national, sector and local government level, these mechanisms were disjointed and could not provide an accurate picture of overall performance (Government of Uganda, 2004b; Thomson et al., 2006).

Accountability for funds injected into the water and sanitation sector was a concern for different categories of stakeholders. However, only a few of these stakeholders were able to make their concerns explicit. One of the earliest documented concerns was expressed by the national Poverty Monitoring and Analysis Unit under the Ministry of Finance and Economic Planning, who were primarily keen to establish the link between investment funds and national poverty reduction (Moller, 2002). Persistent concerns about accountability in the sector, expressed by different stakeholders in different forums, culminated in the commissioning of a technical audit 
of donor-funded projects in the rural water and sanitation sector, whose outputs pointed to inadequate levels of financial accountability and deficiencies in the monitoring functions and structures (Kenny, 2003).

Discussion on sector performance became a main topic of discussion at various policy-making forums in the water and sanitation sector. As a result, the Joint Government/Donor Water and Sanitation Sector Technical Review of March 2003 (Kenny, 2003) recommended that improvement in performance measurement should be a key sector undertaking for the forthcoming fiscal year. An action research project, funded by the UK Department of International Development (DFID) was subsequently commissioned in June 2003 to facilitate a process of developing “...a better focused, balanced and integrated performance measurement framework..." in the Uganda water and sanitation sector (Kenny, 2003: p 7). The researchers started the assignment by exploring the problem situation through review of grey and published sector policy documents, key informant interviews, focus group discussions and observations. Figure 2 shows a rich picture depicting the primary stakeholders, their interrelationships and their concerns as perceived by the author in June 2003 at the start of the action research.

The major stakeholders identified by the study are shown in the rich picture in Figure 2. Box 1 briefly describes the interests of each of the major stakeholder. The motivation for concerns depicted by external stakeholders shown in the rich picture could be classified into three broad categories: (1) accountability for probity (Edwards \& Hulme, 1995), that is honesty and efficiency with which resources are being used; (2) accountability for performance, that is whether the anticipated outcomes, effectiveness and impact have been realised; and (3) accountability for learning, that is those interested in taking lessons on how the sector had managed to develop 
capacity and to use the increased resources effectively. In addition politicians were concerned about popularity with the voters and the international community. The private sector members were concerned about whether they would have a fair share of the "national cake", through winning of contracts for provision of services for the sector organisations. On the other hand, the internal stakeholders were mainly preoccupied with how the whole issue of performance measurement affected continuity of employment in the sector organisations.

\section{Formulating a relevant activity model}

The next step in SSM is to express the real-world situation in the form of a relevant system that uses the concepts of "structure", "process" and the relationship between the two (Khisty, 1995). A relevant system, which is expressed in the form of a root definition, makes it easier to learn more about the situation. A root definition is “... a concise description of a human activity that states what the system is." (Khisty, 1995: p 98). Each of the stakeholders listed in Box 1 had a different perspective of the problem, as captured by the think bubbles in the rich picture shown in Figure 2. If fully analysed, these perspectives would lead to different root definitions. However, the researchers concentrated on the official perspective of the Water and Sanitation Sector Working Group (WSSWG), who provided guidelines on the research question. The WSSWG were therefore taken as the official problem owners.

Although different members of the WSSWG had divergent perspectives on this problem situation, it became apparent during the study that the voice of international donor agencies and Ministry of Finance officials sitting on the committee dominated and overshadowed other divergent views of the problem situation. The research guidelines were quite clear on what transformation process was expected of the intervention: "to develop a better focused, balanced and 
integrated performance measurement framework..." for the sector (Kenny, 2003: p 7). Building on this guideline, the researchers came up with the following root definition:

"A system owned by water and sanitation sector, staffed by sector professionals and accountable to the country, which streamlines and harmonises the existing performance measurement systems and provides information to decisionmakers to enable them make valid evaluations of value-for-money investments and the sector's overall contribution to poverty reduction and ensure equitable allocation of resources between sub-sectors and local government units."

Using the CATWOE (customers-actors-transformation-worldview-ownersenvironment) mnemonic (Checkland \& Scholes, 1990, Khisty, 1995), the abovenamed root definition was unpacked as shown in Box 2.

Having agreed on the root definition, the researchers temporarily de-linked themselves from the problem situation and focussed their thoughts on providing answers to three key leading questions (Checkland, 1999):

- What to do? Improve the existing performance measurement systems (transformation process as depicted by the conceptual model);

- How to do it? A set of sub-systems i.e. individual activities, which, when linked together, result in the transformation process;

- Why do it? Enable decision makers in the sector make valid evaluations for value-for-money of investments and the sector's overall contribution to poverty reduction, and ensure equitable allocation of resources (wider system).

Based on the literature review on performance measurement systems in the public sector(e.g. Greiling, 2005; Holzer \& Kloby, 2005; Radnor \& McGuire, 2004) and review of existing performance measurement systems, the researchers underwent an iterative process to develop a conceptual model, shown in Figure 3. The conceptual 
model is a process model made up of purposeful human activities that (Couprie et al., 2005): (1) are part of a wider system with which they interact; (2) have components that interact with each other such that the effects and actions are transmitted through the system; (3) have decision-making processes; and (4) have measures of performance. In recognition of existing performance measurement systems, the transformation process aimed to compare the "ideal" and current systems. Figure 3 shows that activities classified into five operational sub-systems (numbered 1 to 5 ) and three quality control sub-systems (numbered 6 to 8) are necessary to implement transformation process. The arrows show those activities that are contingent upon others (Checkland \& Scholes, 1990). At this stage, it was not necessary to provide further details of the activities for the sub-systems, as they needed to remain fairly undefined to facilitate debate and negotiation between the implementing staff.

\section{Using the conceptual model to debate the situation and agree actions}

The conceptual model was presented in a three-day stakeholder consultative workshop attended by 65 senior and middle management staff of the water and sanitation sector in August 2003. The proceedings of the workshop were structured as follows:

- Day One: Review of sector objectives, agree on performance themes, assess current performance and brainstorm on the methodology for improving indicators.

- Day Two: Discuss in groups suitable performance themes and indicators for sector and sub-sector objectives, make priority lists of indicators and agree on the way forward for institutional responsibility for monitoring and evaluation.

- $\quad$ Day Three (spaced by one week): Discussion of the draft performance measurement framework presented by the researchers. 
In the brainstorming session, the conceptual model developed by the researchers was used to compare with the current situation. Staff from different departments and organisations were mixed up into discussion groups to cross-fertilise different professional ideas, avoid departmentalising issues and enable a broader outlook of sector performance. Good facilitation skills also contributed to guiding the discussions to concentrate on outputs and outcomes, steering clear of the often controversial topic of resource allocation across different sub-sectors. Three questions were considered at each stage of the discussions: (1) why are things not been done the "ideal" way? (2) what are the reasons for the current methods of work? and (3) how could we improve the situation?

The group discussions came up with several observations. A closer analysis of the existing performance measurement systems showed that the major policy documents articulated dissimilar sector objectives, performance indicators and targets. It was also found that root words of some objectives, such as "service coverage", had different definitions for different stakeholders. Most of the performance data collected was mainly concerned with physical outputs, rather than outcomes and impact. Furthermore, data collection was done at different levels by different uncoordinated agencies, resulting in duplication of effort. There was no central agency that received the data and processed and disseminated it to the different management levels. Furthermore, there were weak linkages between performance measurement of the wider management of the sector, such as human, physical and monetary resource management. Hence, the purposeful human activity models proposed by the consultants aimed to correct some or most of these anomalies.

Comparing the existing situation with the "ideal" model developed by the researchers was an important part of the process. As the discussions on human 
purposeful activities proceeded, participants were able to debate whether the proposed changes will produce the desired results and whether it will be possible to effect the changes in the existing social-cultural environment (Checkland, 1999). The debate also provided an opportunity for stakeholders to "fine-tune" the proposed actions and/or to advance alternative activities. In presenting the conceptual model to the stakeholders, the researchers emphasized the fact that it was meant to provide inspiration to forge a way forward, rather than criticism of the existing situation. The process of participation resulted in buy-in by various stakeholders in the water and sanitation section.

\section{Taking action in the situation to bring about improvement}

The researchers brought together ideas advanced by the participants in the first two days of the consultative workshop to develop an outline sector-wide performance measurement framework. In the space of one week, the researchers carried out the following major activities:

1 Comparison of sub-sector objectives with the national PEAP goals and the MDGs and came up with harmonised sector-wide objectives;

2 Improvement of the existing performance indicators based on the ten performance themes (as agreed in the workshop) of impact, quantity of water, quality of water, access, equity, usage, value for money, affordability, functionality and managerial effectiveness;

3 Adoption of a hierarchy of indicators, starting with community-based indicators, district-level indicators, sub-sector indicators, sector indicators, up to national development-based indicators;

4 Review of the institutional roles for key performance measurement functions and setting up a sector-wide task force on performance measurement. Additional 
information was obtained through further interviews with key stakeholders in the sector;

5 Development of appropriate linkages between departments dealing with planning, operation/maintenance, policy analysis and resource allocation.

The researchers presented their draft report on Day Three of the workshop. The ideas were thoroughly debated in small groups and the plenary session. Some changes were made to the proposals and the researchers eventually came up with a draft version of the Uganda water and sanitation sector performance measurement framework. The draft framework was presented as a working document that needed further improvement and was field-tested in 2003, prior to adopting it as an official document of the sector (Government of Uganda, 2004c). Specifically, it was agreed in the workshop that the performance indicators would be prioritised according to costeffectiveness of data collection, reliability of data and the simplicity of the indicators.

As part of field-testing the draft performance measurement framework, the researchers were requested to support the collection/analysis of data and compilation of the first consolidated performance report for the Uganda water and sanitation sector for the year 2003 (Government of Uganda, 2003b). The task force selected during the consultation workshop supported a team of five consultants who would collect and analyse data and compile the performance report, which was ready in time for the water and sanitation sector performance review conference in September 2003. The report was received with enthusiasm from participants attending the performance review conference and a few recommendations were made to improve its quality. These proposals were analysed and adapted in compilation of the official policy document of the Uganda Water and Sanitation Sector performance measurement framework (Government of Uganda, 2004b). 
Based on the performance measurement framework developed by the researchers, the sector-wide task force has since produced two annual sector performance reports (Government of Uganda, 2004c; 2005a), which show progressive qualitative improvements. The fifth Joint Government of Uganda and Development Partners Sector Review of the Water and Sanitation Sector in Uganda held in September 2005 made the following observation:

"The reporting of the sector outcome and performance was impressive. This year's reporting has greatly improved and presented outcome and performance oriented sector analysis. Its qualitative assessment clearly indicated on the other hand the challenges ahead." Agreed minutes of the fifth Joint Government of Uganda and Development Partners Sector Review of the Water and Sanitation Sector in Uganda, (Government of Uganda, 2005b: p 33)

\section{Summary and conclusion}

Water and sanitation services in low and middle-income countries are delivered in an extremely complex institutional environment. Often, engineers and other physical scientists, who are the principal professionals in the sector are by training orientated to dealing with "hard" problems, that is those that can easily be defined technically and their "what" and "how" defined early on in the methodology. Yet at policy and management level, water sector professionals are often confronted with problems that have a large social and political component, arising from the conflict of stakeholders' meanings, values, interests and objectives. Problems with such characteristics have been described as "soft" problems and according to Professor Checkland and his research colleagues, such problem situations are better handled using SSM. 
A problem situation depicting "soft" characteristics common in many water sectors in middle and low-income countries is the effectiveness and efficacy of existing performance measurement systems to track the progress towards achievement of MDGs. Policy makers in the Uganda water and sanitation sector identified this problem issue and commissioned a team of researchers from the UK in 2003 to strengthen existing performance measurement systems. Applying principles of SSM, the researchers, with the full participation of key stakeholders in the sector and the support of a sector-wide task force, developed and field tested a performance measurement framework that (1) harmonised definitions, concepts and objectives across sector institutions; (2) prioritised indicators and targets based on key performance themes; and (3) allocated roles and responsibilities for data collection, analysis, distribution and use.

Based on the evaluation by observation of stakeholders attending the annual sector performance review conferences, the quality of annual sector performance reports has progressively improved since this intervention three year ago. There have been structural, procedural and policy changes effected to improved performance measurement in the sector. However, for these changes to be sustainable, there also need to be positive changes in the attitudes of the stakeholders, which will eventually lead to changes in organisational values, roles and norms. Such attitudinal changes happen slowly over a relatively longer period of time.

\section{Acknowledgements}

This action research was sponsored by the UK Department of International Development as part of a study for the benefit of developing countries. The views expressed are not necessarily those of DFID. The author is grateful for the efforts of 
all members of the research team (both international and local), as well as the stakeholders in the Uganda Water and Sanitation Sector who participated in the study.

\section{References}

Checkland, P. (1985). Achieving desirable and feasible and feasible change: An application of soft systems methodology. Journal of the Operational Research Society, 36, 821-831.

Checkland, P. (1993). Systems Thinking, Systems Practice. John Wiley and Sons,.

Checkland, P. (1999). Soft Systems Methodology: a 30-year retrospective. John Wiley and Sons, Chichester.

Checkland, P. \& Scholes, J. (1990). Soft Systems Methodology in Action, Chichester, John Wiley and Sons.

Couprie, D. Goodbrand, A., Li, B. \& Zhu, D. (2005). Soft Systems Methodology, available at http://sern.ucalgary.ca/courses/seng/613/F97/grp4/ssmfinal.html, accessed on 30 March 2005.

Edwards, M. \& Hulme, D. (1995). Performance and accountability: introduction and overview. In: Non-governmental Organisations - Performance and Accountability. Beyond the Magic Bullet, Edwards, M. \& Hulme, D. (eds.). Earthscan, London.

Evans B., Hutton G. \& Haller L. (2004). Closing the Sanitation Gap - the Case for Better Public Funding of Sanitation and Hygiene. Background paper for the OECD Round Table on Sustainable Development meeting on water and sanitation, 9-10 March 2004, Paris.

Government of Uganda (2003a) Uganda's progress in attaining the PEAP targets - in the context of the Millennium Development Goals, available at http://siteresources.worldbank.org/UGANDAEXTN/Resources/CG_2003_Go 
U_PEAP targets.pdfGovernment of Uganda (2003b). Water and Sanitation in Uganda: Measuring performance for improved service delivery; Ministry of Water Lands and Environment, Kampala Uganda.

Government of Uganda (2004a). Poverty Eradication Action Plan (2004/5 - 2007/8).

Ministry of Finance, Planning and Economic Development, Kampala Uganda, available at http://www.finance.go.ug/docs/PEAP\%202005\%20Apr.pdf , accessed on 14 June 2006. Government of Uganda (2004b). Water and Sanitation Sector Performance Measurement Framework. Ministry of Water Lands and Environment, Kampala Uganda.

Government of Uganda (2004c). Water and Sanitation Sector Performance Report 2004. Ministry of Water Lands and Environment, Kampala Uganda. Government of Uganda (2005a). Water and Sanitation Sector Performance Report 2005. Ministry of Water Lands and Environment, Kampala Uganda.

Government of Uganda (2005b). 5th Joint Government of Uganda/Development Partners Sector Review of the Water and Sanitation Sector in Uganda. Conference Report, Ministry of Water Lands and Environment, Kampala Uganda.

Greiling, D. (2005). Performance measurement in the public sector: the German experience, International Journal of Productivity and Performance Management, 54 (7), 551-567.

Grigg, N.S. (1997). Systemic analysis of urban water supply and growth management. Journal of Urban Planning and Development, 123, (2), 23-33.

Holzer, M. \& Kloby, K. (2005). Public performance measurement: An assessment of state-of-the-art and models for citizen participation. International Journal of Productivity and Performance Management, 54 (7), 517-532. 
Kenny, S. (2003). The Case of Improving Performance Measurement in the Uganda Water and Sanitation Sector. Unpublished discussion paper for the Uganda Water and Sanitation Sector Working Group, March 2003.

Khisty, C.J. (1995). Soft-systems methodology as a learning and management tool, Journal of Urban Planning and Development. 121 (3), 91-107.

Moller, L.C. (2002). Is the Water Sector Delivering? Unpublished position paper by the Poverty Monitoring and Analysis Unit, Government of Uganda.

Radnor, Z. \& McGuire, M. (2004). Performance management in the public sector: fact or fiction? International Journal of Productivity and Performance Management, 53 (3), 245-260.

Robinson, M. \& Thin, N. (1993). Project Evaluation: A guide for NGOs. Overseas Development Administration Joint Funding Scheme. NGO Unit, Glasgow.

Seppälä, O.T. (2002). Effective water and sanitation policy reform implementation: need for systemic approach and stakeholder participation, Water Policy, 4, $367-388$.

Thomson, M., Okuni, P. \& Sansom, K (2006). Sector performance reporting in Uganda - from measurement to monitoring to management. In: Maximising the Benefits from Water and Environmental Sanitation. Kayaga, S (ed.). 31st WEDC International Conference, Loughborough University, UK, available at http://wedc.lboro.ac.uk/conferences/pdfs/31/Thomson.pdf, accessed on 16 June 2006.

United Nations Development Programme (UNDP) (2005). Human Development Report 20 - International cooperation at a crossroads: Aid, trade and security in an unequal world. UNDP, New York. 
WELL (2004). Water Supply and Sanitation Sector Monitoring: A new decade to measure, available at http://www.lboro.ac.uk/well/resources/Publications/Briefing\%20Notes/BN\%2 0Sector\%20Monitoring.htm, accessed on 14 June 2006.

WHO/UNICEF (2000). Global water supply and sanitation assessment report 2000. Joint Monitoring Programme, Geneva: WHO.

Wilson, B. (1984) Systems: Concepts, Methodologies and Applications. John Wiley, Chichester. 
Fig. 1. Stages of SSM (adapted from Checkland, 1999).

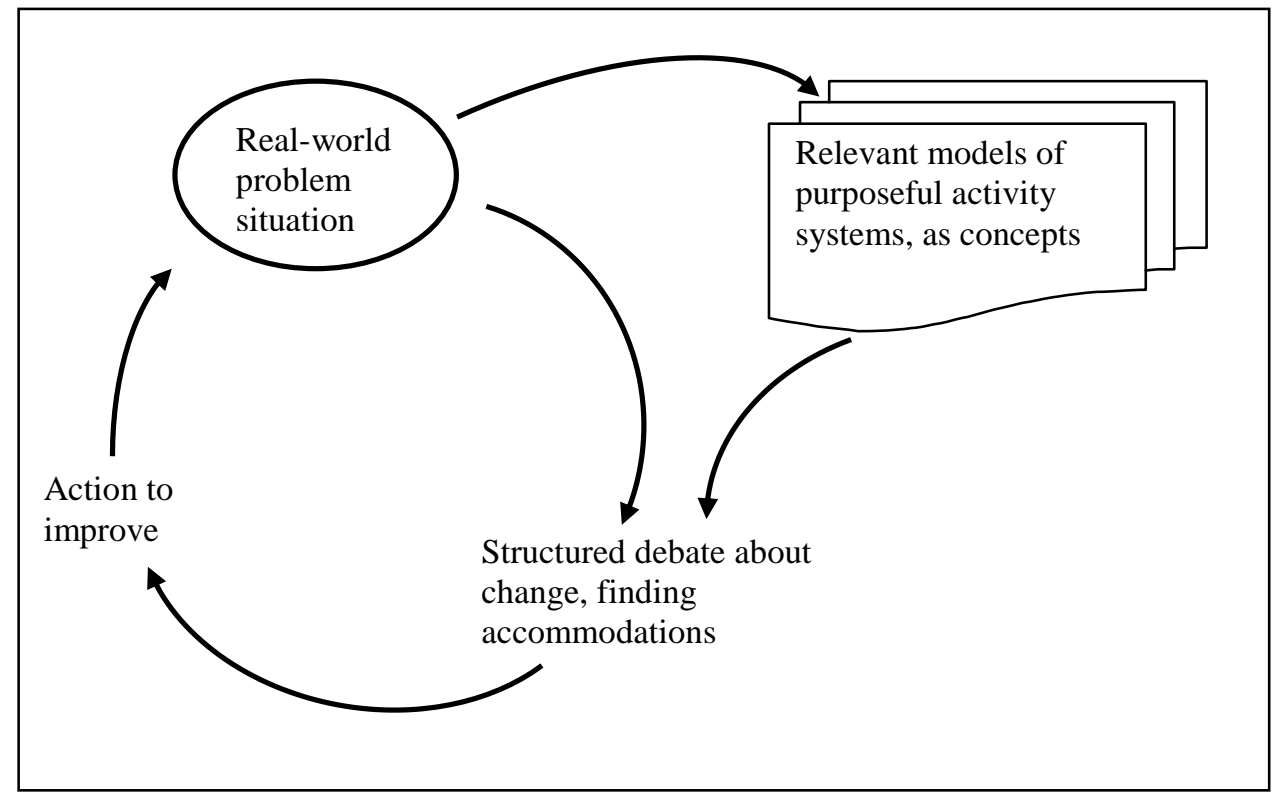


Fig. 2. A rich picture showing primary stakeholders in the Uganda water and sanitation sector, their interrelationship and their major concerns in June 2003.
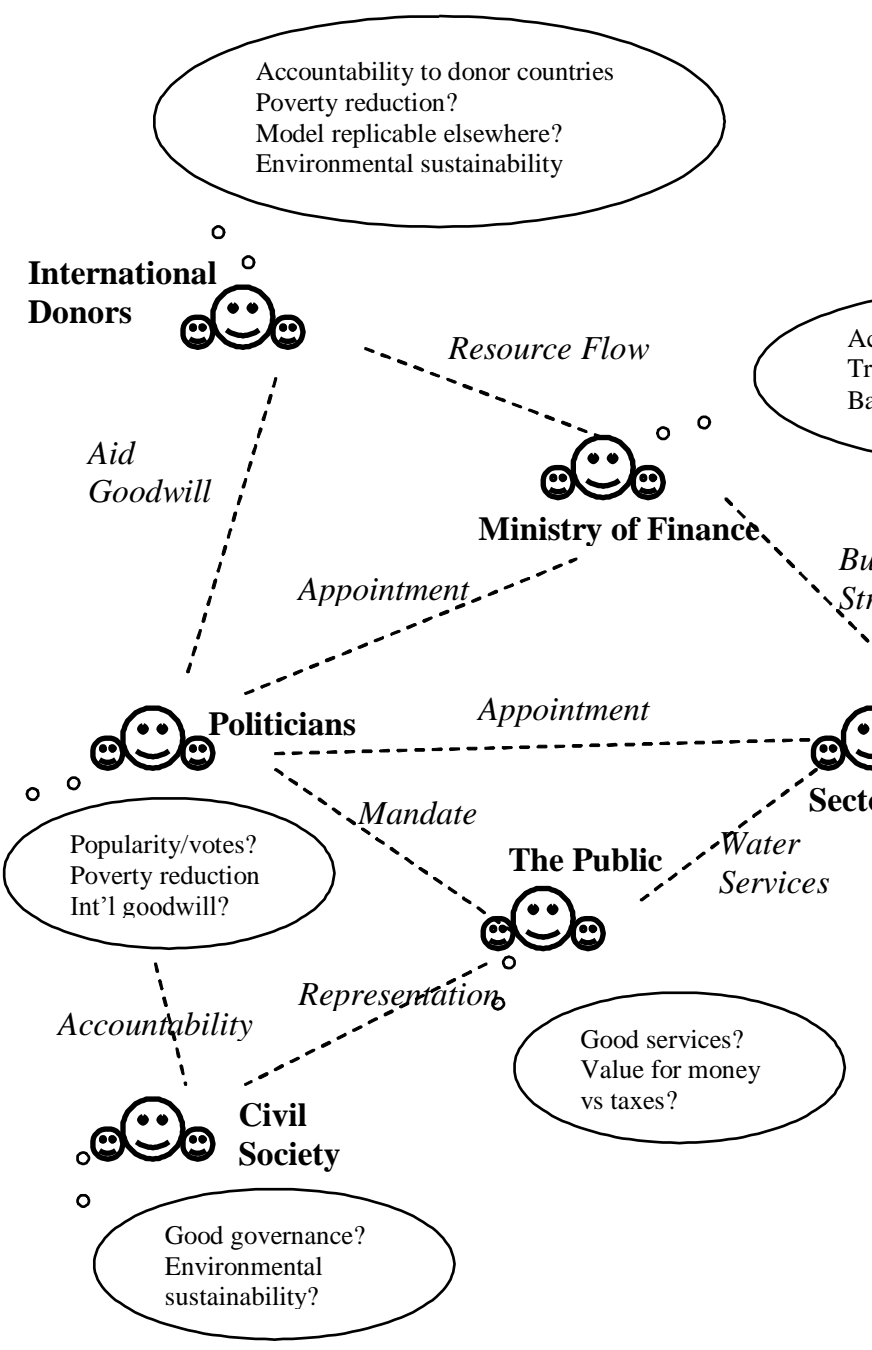

Accountability to Politicians Tracking of poverty targets Balancing of budgets 
Fig. 3. Conceptual model of a system to improve the performance measurement framework in the Uganda water and sanitation sector.

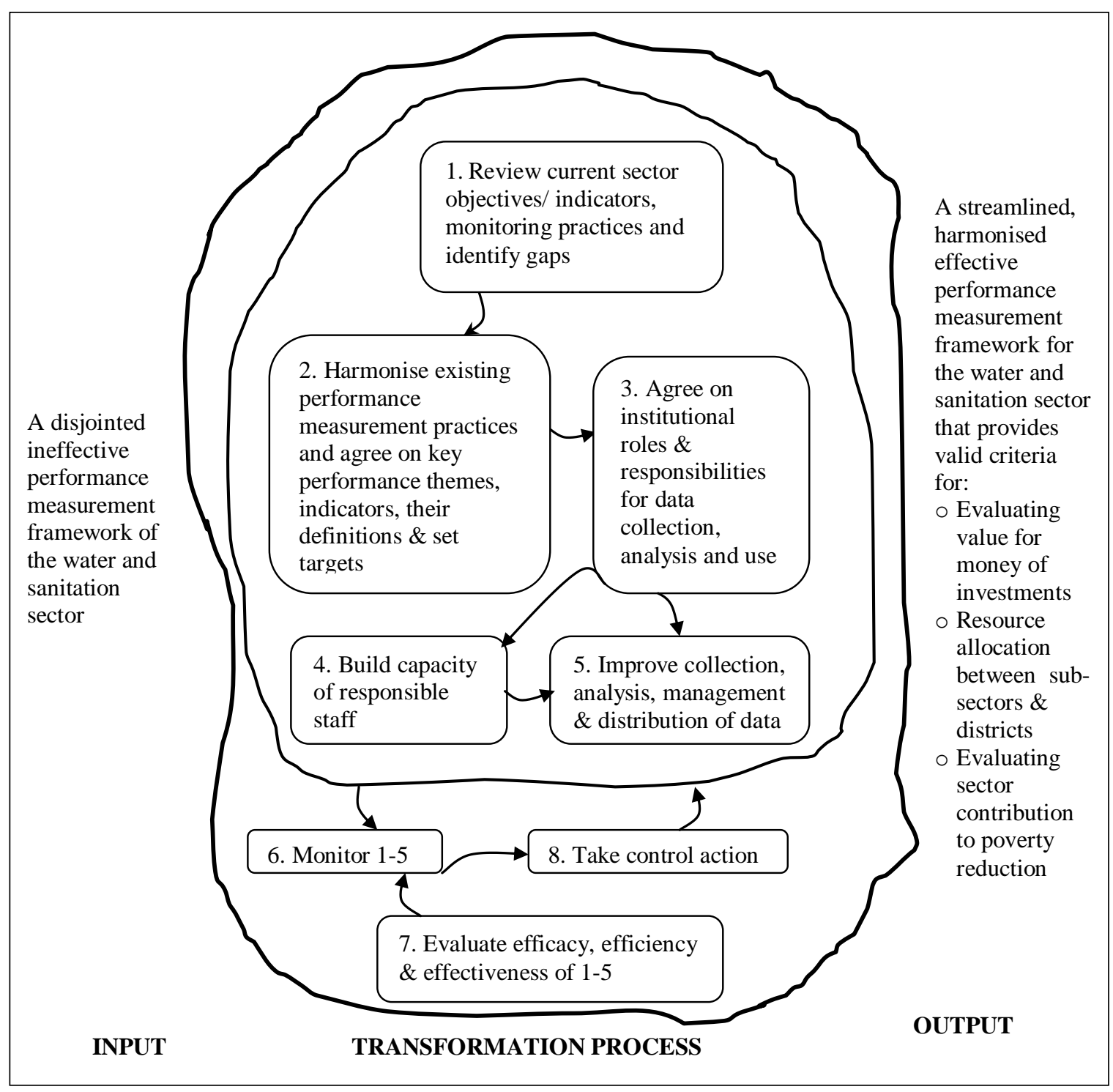




\section{Box 1: Brief description of the interests of the major stakeholders in the improvement of the water sector performance measurement framework}

1 Members of the public, who are the beneficiaries of the services delivered by sector institutions.

2 Representatives of international donor agencies, who provide the bulk of investment funds in the sector. Foreign embassy technical officers of the major bilateral donor countries, World Bank and UNICEF representatives are members of the Water and Sanitation Sector Working Group (WSSWG), the highest policymaking committee in the sector.

3 Water desk officers based in the Budget Section of Ministry of Finance and Economic Planning, who also sit on the WSSWG and allocate poverty alleviation investment funds and recurrent budgets.

4 The Poverty Monitoring and Analysis Unit of the Ministry of Finance and Economic Planning, who make inputs into the national policies and manage the national Poverty Eradication Action Plan.

5 Managers and employees of the sector, who implement the policies at different hierarchal levels. These could further be categorised into different sub-sectors and institutions. All sub-sectors and institutions are represented on the WSSWG.

6 Politicians, such as the government executives, members of parliament and other elected representatives.

7 Members of civil society, such as NGOs and consumer organisations, who champion the interests of members of the public not represented by other organisations. The Uganda Water and Sanitation NGO Forum (UWASNET), the 
organisation coordinating NGOs working in the water and sanitation sector and WaterAid are members of the WSSWG.

8 The private sector, which provides consultancy, construction and other services to the water and sanitation sector. Currently, there is a representative of the private sector on the WSSWG.

\section{Box 2. Root definition of the relevant system for learning the situation}

Customers: managers and policy makers in the sector and the national planning department

Actors: $\quad$ water and sanitation sector professionals

Transformation: disjointed ineffective performance measurement systems of the water and sanitation sector transformed into a streamlined, harmonised effective performance measurement framework

Worldview: Effective performance measurement of programme activities in the water and sanitation sector will enhance accountability for probity and effectiveness.

Owners: $\quad$ The Water and Sanitation Sector Working Group

Environmental Constraints: relevant staff support and buy into the transformation process, acquire the necessary skills and are receptive to institutional coordination 